\title{
Kazimierz Kłosek
}

dr hab. inż., prof. nzw.

Politechnika Śląska, Wydział Budownictwa; Wyższa Szkoła Techniczna w Katowicach kazimierz.kłosek@pols1.pl

DOI: 10.35117/A_ENG_16_11_06

\section{Railway subgrade in mining areas reinforced with geosynthetics}

\begin{abstract}
The study presents basics of designing and forming earthen structures for transportation purposes on ground with poor load capacity, mainly in mining areas. Main types of retaining structures, steep slopes, and embankments reinforced by the technology will be presented. The paper also describes the mechanism of functioning these structures with additional use of geosynthetic reinforcement within the road surfaces and railway track structures, especially in the areas where continuous (subsiding troughs) and non-continuous (collapses, fissures) mining damage occurs. The basic selection criteria of soil material, reinforcement, and erosion-preventing structures will be characterized. The study contains basic principles for making check calculations of critical load capacity conditions and usability of structures for their assumed life service. Specific and executed structures will be presented, including high embankments for motorways (highways) and railway embankments, located in the areas that are subject to intense mining activity.
\end{abstract}

Keywords: mining area, geosynthetics, transportation earthen structure

\section{Introduction}

Building on mining areas is in many countries a specific field of engineering activity $[3,9]$. Deformations in the mining area make that both mining and construction prevention is particularly important. The main objective of mining prevention is to minimize the deformation of the surface and thus the damage caused on the area with located various buildings as well as communication and hydrotechnic objects. This range of prevention is realized by the use of appropriate technology for extracting minerals, reduction of partial or total excavation under the protected objects or by setting up so-called protective pillars. On the other hand, construction prophylaxis involves the shaping and securing the construction of building objects to minimize damages caused mainly by unit horizontal deformations of the ground with a thickening or loosening character [4,6]. Objects defined conventionally as a point, such as all kinds of buildings, industrial halls, chimneys, bridges, etc. have different nature of cooperation with the mining ground than linear objects such as roads, railways, dams and embankments of rivers, underground pipelines, cable lines, etc. In this paper, we analysed the communication linear objects, mostly embankments and steep slopes with the character of resistant walls. Their load bearing capacity and stability in the mining areas is subjected to a significant reduction which could seriously jeopardize the sustainability of these structures and the safety of their use because of intensive traffic on roads and rails.

\section{The essence of mining damage in communication earthen buildings}

Deformation of surface mining area is classified in view of their intensity (in 0 - 5 category, and its character as a continuous or non-continuous deformation in the form of cracks, craters, hollows, faults etc. This classification allows evaluating the estimated change in the geometric parameters of the area and objects localized on its surface. In the analysed case there are specific line (communication) structures, as opposed to point objects, which include e.g. 
buildings. In the following part of this paper, we focused to the problem of the so-called continuous deformations due to their predominant extent and frequency.

Continuous mining subsidence pan is described by five basic parameters [7] :

- subsidence of mining area, $\mathrm{w}[\mathrm{m}]$,

- slope, $\mathrm{T}=\mathrm{dw} / \mathrm{dx}[\mathrm{mm} / \mathrm{m}]$ or $[\% \mathrm{o}]$,

- surface curvature, $K=\mathrm{d}^{2} \mathrm{w} / \mathrm{dx}^{2}[1 / \mathrm{km}]$,

- horizontal displacement, u [m],

- unit horizontal deformation $\varepsilon=\mathrm{du} / \mathrm{dx}[\mathrm{mm} / \mathrm{m}]$ or $[\% \mathrm{o}]$, loosening $\varepsilon_{\mathrm{r}}$ and thickening $\varepsilon_{\mathrm{z}}$

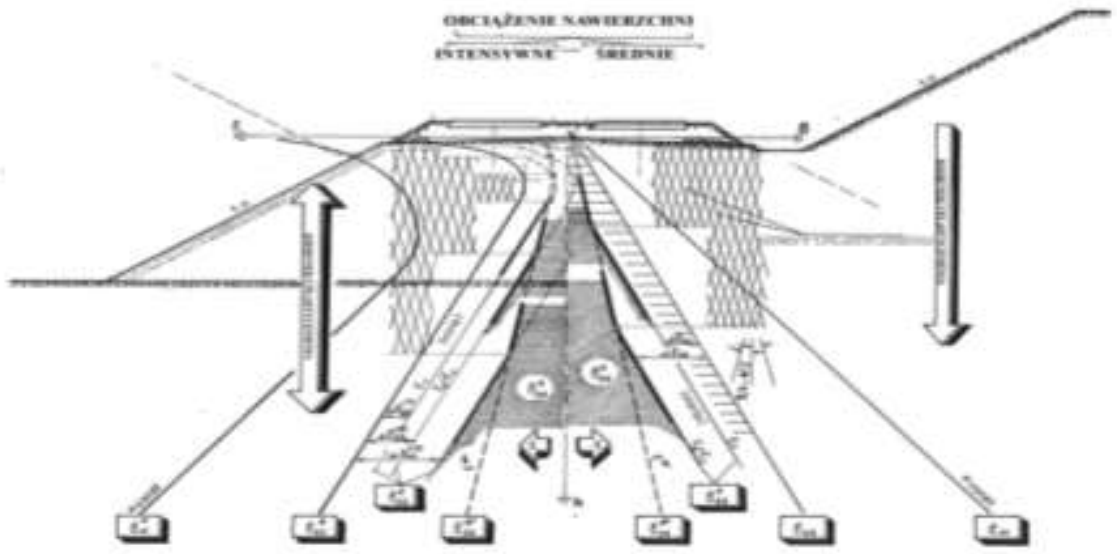

1. Development of plasticity zones with unreinforced soil surface and subgrade on mining areas in conditions of horizontal loosing deformations $\varepsilon[4,7]$

Deformations are accompanied by a reduction of strength parameters of soil. Technical

literature of this problem [5] and numerous studies have shown that these parameters of ground in the active mining areas cannot be regarded as constants, because they are subjected to characteristic changes that can be described by the relation:

$$
\tau_{\max }=\sigma^{\prime}{ }_{11} \operatorname{tg} \Phi_{\varepsilon}+c_{\varepsilon}=\sigma^{\prime}{ }_{11} \operatorname{tg} \Phi_{\varepsilon}+c_{s}+\beta(t) \sum \mathrm{w}>\tau_{\varepsilon}{ }^{r}=\sigma^{\prime}{ }_{11} \operatorname{tg} \Phi_{\varepsilon}+\beta(t) \sum \mathrm{w}>\tau_{\min }=\sigma^{\prime}{ }_{11} \operatorname{tg} \Phi_{\varepsilon}
$$

where:

$\sigma^{\prime}{ }_{11}$ - effective normal stress,

$\mathrm{c}_{\mathrm{s}} \quad-$ the structural part of the overall consistency of the soil, so called strengthening coherence; occurring as a result of concentration processes in the bulk soils,

$\Sigma \mathrm{w}$ - the consistency of the soil caused by water-colloid ties with moisture $\mathrm{w}_{\tau}$, so-called primary cohesion; it is substantially reduced in the course of soil mining in excavations and transport

$\beta(t)$ - coefficient taking into account the intensity of the deformation process of the mining area; $1>\beta(\mathrm{t})>0$;

in the studied case it can be accepted that $\beta(\mathrm{t})=0$, other markings as in Fig. 1:

$\sigma_{22}^{*}$ - horizontal stresses, i.e. total, taking into account the own load of soil (struts), weight of surface and component of the axial load of the rolling stock,

$\sigma^{\mathrm{gr}}{ }_{22}$ - boundary horizontal stress in the so-called a total, active state of stress $\left(\sigma^{\mathrm{min}}{ }_{22}\right)$ : 


\section{Numerical model}

Reinforcements adopted to model in the form of mattress of aggregates, and geosynthetic (geogrid) differed in tensile strength: $40 \mathrm{kN} / \mathrm{m}$ - geogrid from PP, $400 \mathrm{kN} / \mathrm{m}$ - geogrid from PVA and $800 \mathrm{kN} / \mathrm{m}$ - geogrid from Aramide.

According to European guidelines EC7 [1,8], as a strength parameter of studied geogrids in each modelling cases, we assumed the computational long-term tensile strength $F_{d}$ determined by the formula (2):

$$
F_{d}=\frac{F_{k}}{A_{1} \cdot A_{2} \cdot A_{3} \cdot A_{4} \cdot \ldots A_{n} \cdot \gamma} \quad[k N / m]
$$

where:

$F_{k} \quad$ - immediate value of tensile strength $[\mathrm{kN} / \mathrm{m}]$,

$A_{1 \ldots n}$ - material coefficients,

$A_{l} \quad$ - coefficient taking into account creep,

$A_{2} \quad$ - coefficient taking into account mechanical damage of the material during incorporation and transport of geosynthetic,

$A_{3} \quad$ - coefficient taking into account way of combining layers of geosynthetics,

$A_{4} \quad$ - coefficient taking into account the environmental impact,

$\mathrm{A}_{\mathrm{n}} \quad$ - coefficients taking into account other factors, such as mining influence and shocks of seismic and para-seismic type induced by mining activities, 1.75 .

$\gamma \quad$ - coefficient of material safety in the method of global safety coefficient $\gamma=$

Depending on the type of polymer from which the geogrid was made we assumed (Bauen 2003) corresponding values of material coefficients (Tab. 1).

Tab. 1. Material coefficients used in calculations

\begin{tabular}{|c|l|l|c|}
\hline \multirow{2}{*}{ Material coefficient } & \multicolumn{3}{|l|}{ Geosynthetic material } \\
\cline { 2 - 4 } & PP & PVA & Aramide \\
\hline $\mathrm{A}_{1}$ & 5,0 & 2,5 & 2,5 \\
\hline $\mathrm{A}_{2}$ & 2,0 & 2,0 & 2,0 \\
\hline $\mathrm{A}_{3}$ & 1,0 & 1,0 & 1,0 \\
\hline $\mathrm{A}_{4}$ & 3,3 & 2,0 & 3,3 \\
\hline
\end{tabular}

Geotextile products have different physical and mechanical properties, so their correct selection requires special knowledge. For this reason, the relevant guidelines require verification of two conditions especially for bulk buildings and assumed period of their exploitation:

- tensile strength (computational $\mathrm{F}_{\mathrm{d}}$ ),

- permissible strain.

The consequence of a reduced durability of the reinforcement material may be significant shortening the life of the object and even its fault. A characteristic feature of some geotextiles, such as PP/PET and HDPE, included in the relevant standard is variable during the stiffness of strained geosynthetic due to the rheological characteristics of the material. 


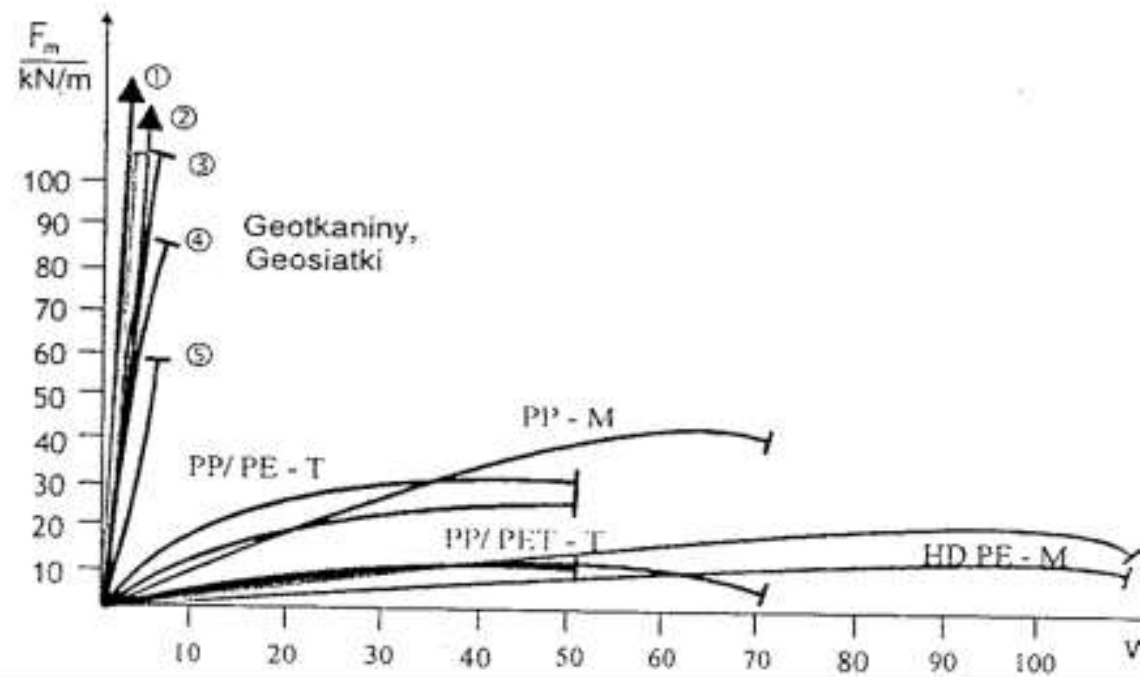

2. The dependence of tensile force $\mathrm{F}[\mathrm{kN} / \mathrm{m}]$ from elongation $\mathrm{v}[\%]$ for different geotextile products (1-Aramide, 2-polyester, 3-synthetic glass, 4- polyester, 5- polyethylene with high density)

Numerical model of earth building situated in the mining are was created using the program Z_Soil [2] belonging to the group of programs based on the finite element method. It was assumed that the embankment is located on a two-track railway line (Fig. 3). For individual model layers of substrate, embankment and pavement structures were adopted appropriate geotechnical and material parameters (Tab. 2).

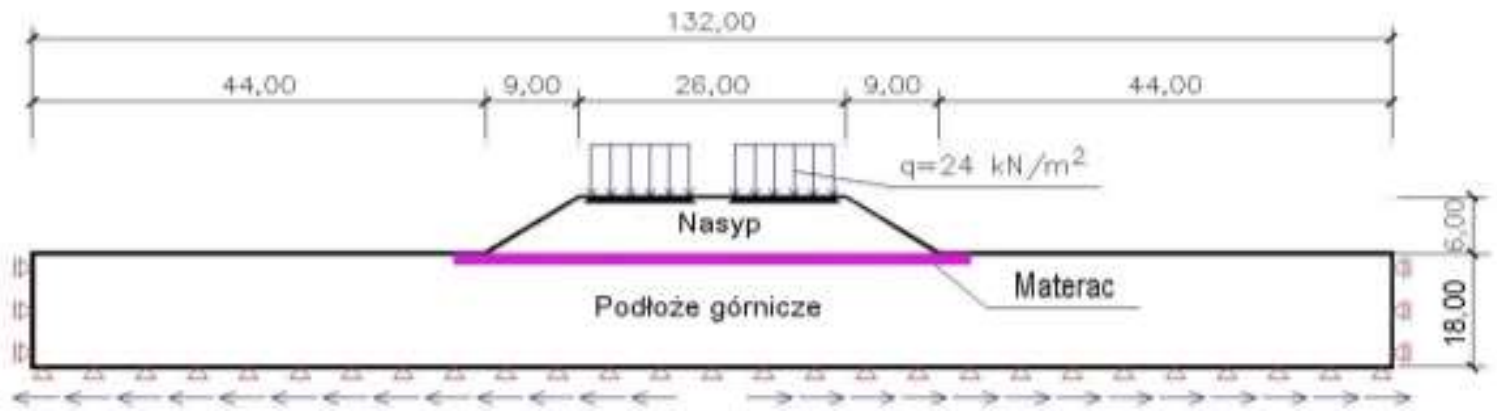

3. Calculation schema for reinforced embankment in the level of the base (traffic light of vehicles) 
Tab. 2. Geotechnical parameters of individual layers of the model assumed in numerical calculations

\begin{tabular}{|c|c|c|c|c|c|c|c|c|c|c|}
\hline Layer & \multicolumn{2}{|c|}{ Material model } & \multicolumn{2}{|c|}{$\begin{array}{l}\mathrm{E} \\
{[\mathrm{MPa}]} \\
\end{array}$} & \multicolumn{2}{|c|}{$\begin{array}{l}\square \\
{\left[\mathrm{kN} / \mathrm{m}^{3}\right]}\end{array}$} & $v$ & \multicolumn{2}{|c|}{$\mathrm{C}[\mathrm{kPa}]$} & $\Phi\left[^{\circ}\right]$ \\
\hline Substrate & \multicolumn{2}{|c|}{ Coulomb-Mohr } & \multicolumn{2}{|c|}{30} & \multicolumn{2}{|l|}{22} & 0,3 & \multicolumn{2}{|l|}{$33^{*}$} & 18 \\
\hline $\begin{array}{l}\text { Earthwork } \\
\text { (NB) }\end{array}$ & \multicolumn{2}{|c|}{ Coulomb-Mohr } & \multicolumn{2}{|c|}{60} & \multicolumn{2}{|l|}{18} & 0,3 & \multicolumn{2}{|l|}{20} & 30 \\
\hline Protected & \multicolumn{2}{|c|}{ Coulomb-Mohr } & \multicolumn{2}{|c|}{200} & \multicolumn{2}{|l|}{30} & 0,3 & \multicolumn{2}{|l|}{3} & 42 \\
\hline Ballast & \multicolumn{2}{|l|}{ Elastic } & \multicolumn{2}{|c|}{2800} & \multicolumn{2}{|l|}{30} & 0,3 & \multicolumn{2}{|l|}{-} & - \\
\hline Geogrid & \multicolumn{5}{|c|}{ Anisotropic membrane } & \multicolumn{3}{|c|}{$\begin{array}{l}\text { Dependent on } \\
\text { geogrid }\end{array}$} & $\begin{array}{l}\text { Mel } \\
\mathrm{PP} / 1 \\
\text { geo }\end{array}$ & $\begin{array}{l}\text { parameters } \\
\text { dependent on } \\
\text { ording to [2] }\end{array}$ \\
\hline $\begin{array}{l}\text { Aggregate } \\
\text { in } \\
\text { mattress }\end{array}$ & $\begin{array}{l}\text { Coulomb- } \\
\text { Mohr }\end{array}$ & \multicolumn{2}{|c|}{120} & \multicolumn{3}{|l|}{20} & 0,3 & \multicolumn{2}{|l|}{8} & 38 \\
\hline
\end{tabular}

"the value of consistency ' $c$ ' was reduced according to the respective values of unit deformation $\varepsilon$. the reduced value of the ground consistency was respectively: $0,92(\varepsilon=0,3 \mathrm{~mm} / \mathrm{m}), 0,75(\varepsilon=1,5 \mathrm{~mm} / \mathrm{m})$; $0,67(\varepsilon=3,0 \mathrm{~mm} / \mathrm{m})$ of initial consistency.

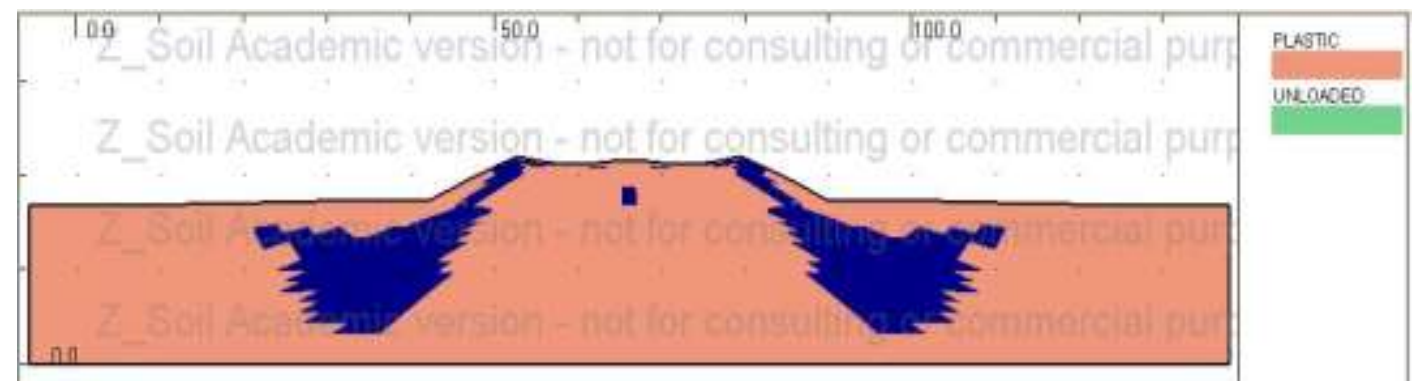

4. Deformation of the cross-section and development of plasticity areas in the model without geogrid mattress; transverse creep of mining area $\varepsilon=1,5 \mathrm{~mm} / \mathrm{m}$.

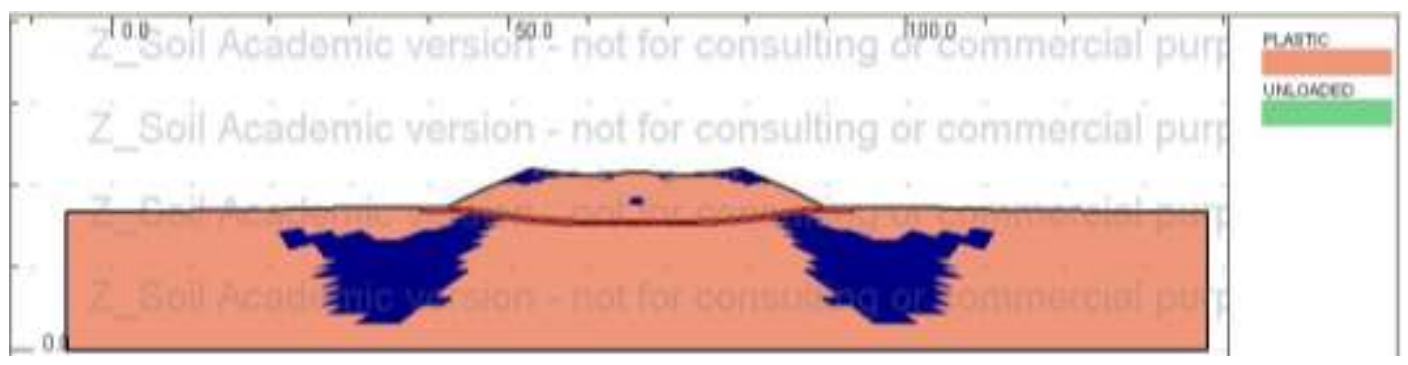

5. Deformation of the cross-section and development of plasticity areas in the model with mattress of PP geogrid; $\varepsilon=1,5 \mathrm{~mm} / \mathrm{m}$. 

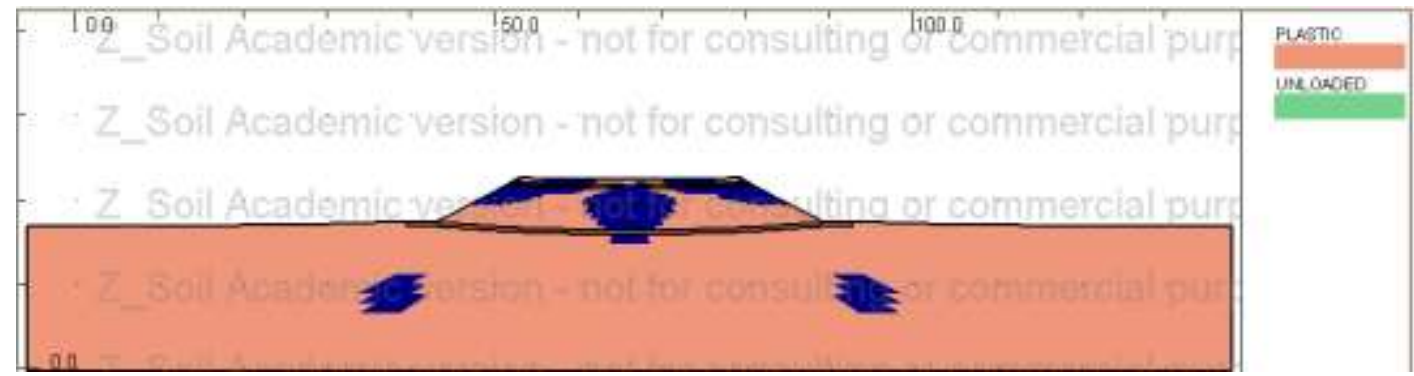

6. Deformation of the cross-section and development of plasticity areas in the model with double mattress of PVA geogrid; $\varepsilon=1,5 \mathrm{~mm} / \mathrm{m}$.
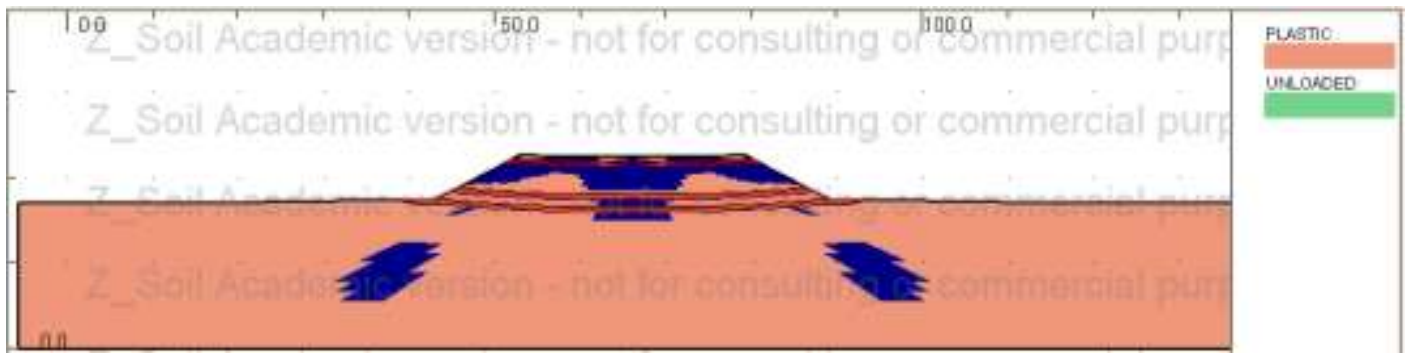

7. Deformation of the cross-section and development of plasticity areas in the model with triple mattress of PVA geogrid; $\varepsilon=1,5 \mathrm{~mm} / \mathrm{m}$.

\section{Analysis of results}

Based on the results of numerical studies, it can be concluded that the development of plastic deformation zone is very intense, and in the absence of strengthening the base of earthwork it covers its entire body already for the intensity of horizontal loosening deformations $\varepsilon=1,5 \mathrm{~mm} / \mathrm{m}$. In the case of strengthening the base of the embankment by broken stone mattress in the coat of polypropylene (PP) geogrid, characterized by considerable extensibility, plastic zones for $\varepsilon=1,5 \mathrm{~mm} / \mathrm{m}$ cover the upper layers of the embankment which will lead to surface defects. Reinforcement of long-term communication earthen buildings in mining areas using geogrids made from PP/PE/HDPE is therefore inappropriate, because they can be used only for temporary objects. Replacement of these materials for PVA affects significantly the efficiency of the construction of embankments for prevention in mining areas. For double geogrid located at the base of the embankment and at its crown, under the ground, the embankment with surface retain features of elastic material in a much larger extent, even for $\varepsilon=1,5-4,5 \mathrm{~mm} / \mathrm{m}$. In the case of three-layer mattress, the situation is even more favourable. It should be noted that carried out numerical simulations have been validated in field conditions where they received full confirmation. Results of these studies may also be useful for seismic areas in relation to the localized earthen communication structures, embankments of rivers and reservoirs, steep slopes, etc.

\section{Conclusions}

The presented results of the numerical analysis of interaction communication and hydrotechnic earthen objects with mining ground indicate that the essential principles of building prevention should rely on the use of reinforcement of soil with geosynthetics. The effectiveness of these reinforcements is primarily determined by the appropriate static analysis of the structure and the selection of reinforcement with regard to its long-term durability and reliability of works of construction in the whole exploitation period, i.e. not shorter than 50-120 years. 


\section{Source materials}

[1] Bauen mit Geokunststoffen (2003). Ein Handbuch fur den Geokunstoff - Anwender. Verbund fur Geokunstoffe (SVG),

[2] Z_Soil ${ }^{\circledR}$.PC v2007 3D Academic, Zace Services Ltd, Lausanne, Switzerland.

[3] [3] Klosek K.(2007): Highway and Rail Track Foundations In Mining Site Areas. Proceedings of the Int. Symp. On 'Innovation \&Sustainability of Structures ISISS'2007;Shanghai Nov.28-30,2007. Printing-2008 by Southeast University Press, Nanjing, China, , vol2 p.856-863

[4] Klosek K. (1999). Slope stability of rectify coal waste embankments on mining areas. Proceedings $16^{\text {th }}$ Annual National Meeting of the ASSMR, Scottsdale, AR,USA,

[5] Klosek K.(1996). Use of geosynthetics for strengthening road surface and subbase in areas with the mining activity. Proc. of the Int.Symp. on 'Earth Reinforcement', vol.I Fukuoka, Japan, Ed. - Balkema, Rotterdam: 609-614

[6] Klosek K. (1994). Prevention of damage to highways and railroads in mining areas. Proceedings of the Int.Land and Mine Drainage Conf., Pittsburgh, PA,USA, April 2429,1994:101-110.

[7] Klosek K. (2001).Extreme impact of underground mining on linear transportation structures. Proceedings $18^{\text {th }}$ Conf. Of ASSMR, Albuquerque, NM,USA, June 3-7,2001: $142-150$

[8] Kłosek K.: Badania geosyntetyków w budownictwie kolejowym. WST - Współczesne Systemy Transportowe.1/2016, Katowice; s.26-33

[9] Klosek k.: Foundations model for transportation infrastructure in mining site areas. Proceedings of the $6^{\text {th }}$ International Conference On Structural Engineering, Mechanics and Computation Cape Town - South Africa, Ed. CRC 2016 , Balkema - Taylor\&Francis Group, London UK 